\title{
Science and Policy
}

\author{
by Lynne Trulio
}

\section{Restoration ecologists}

\section{and policymakers}

\author{
need to work
}

\section{together, despite}

\author{
the uncertainties
}

\author{
of our science.
}

$T_{\mathrm{p}}^{\mathrm{h}}$ he relationship between science and policy was an important theme of the Society for Ecological Restoration 1997 Annual Conference in Fort Lauderdale, Florida, and the discussions surrounding this issue gave me reason to contemplate the interaction between resource managers and scientists working in the field of ecological restoration. Key to sparking my interest was a plenary talk by Colonel Terry Rice, who served three years as Commander and District Engineer for the Jacksonville District Office of the U.S. Army Corps of Engineers before his retirement in 1997. Col. Rice noted that managers and decisionmakers often have trouble integrating scientific information into policy decisions. During his work in south Florida, which is home to such large-scale, federally-managed projects as the Kissimmee River and Everglades National Park restorations, he found that data were often incomplete and conflicting. He told the audience that his greatest frustration was his inability to get scientists to give him the specific answers he needed to implement policy. His and other discussions revealed both the interaction and the tensions that develop between scientists and policymakers while carrying out these projects.

In this commentary, I consider some of the problems that Col. Rice noted and the role that uncertain scientific datadata that are both variable and incomplete-play in setting managers and scientists at odds with one another. I also offer a perspective on how both groups can overcome these problems and survive in a world without exact answers.

\section{Science, Management and Uncertainty}

Whenever restorationists use ecological data to support policy and management decisions, they face the same problems of uncertainty that ecologists and managers have in the past (Haeuber and Ringold, 1998). This problem, and its subsequent frustrations, stem, in part, from the practice and culture of science. Scientists view data as inherently incomplete and variable. No matter how much data they have, scientists feel they need more information in order to understand a system well enough to restore or manage it successfully (Norton, 1998). The culture of science is one in which scientists add pieces to a puzzle that is never completed, but which becomes clearer as each piece is added. In addition, current scientific practice is predicated on the tenet that no hypothesis is ever proven true-only rejected or supported. Even with the best data and a well-supported hypothesis, scientists are not able to give managers exact answers to ecological questions related to management and policy issues. Natural variability in ecological systems ensures that ranges, means and standard deviations, and estimates are basically all that ecologists can supply.

Managers operate in a very different culture-working with goals that include implementing policies and programs, and then measuring the success of projects that arise from those decisions. Managers often expect scientists to provide more or less exact, practical answers to their questions (Carpenter, 1995) and are frustrated 
when they find the answers are seldom exact and often inconsistent. Even worse, they may find that there are no answers to their questions because scientists are investigating questions quite different from the ones they want addressed. Clearly, scientists and resource managers bring different expectations of scientific data to the process.

Melding these divergent views is a challenge and a goal for restoration. Multiple values-policy, management, science, values of indigenous peoples, economics-must be interwoven to achieve the renewal of ecosystems. Laura Jackson of the University of Northern lowa and her colleagues (1995) noted that a form of cultural pluralism is an integral part of any conception of ecological restoration. This means including people from various religious or ethnic backgrounds and finding ways for them to work together effectively. It also means finding ways for the "cultures" of science and policymaking to have a meaningful dialogue. This becomes increasingly important as policy-driven projects become larger and more commonplace.

\section{Setting Goals, Developing Meaningful Dialogues}

In setting goals to measure the success of restoration or mitigation projects, resource managers have found that specific compliance targets, such as percent plant cover or the presence of a particular plant species, are effective for assessing whether a project has met policy objectives. However, these compliance requirements are usually static targets, or ecological structure parameters, that represent single measurements of existing conditions at a particular time, and only generally assess ecological functions (Josselyn et al., 1990). Joy Zedler has noted, however, that a major problem with specific targets based on static measures is that they may indicate very little about the functioning and longevity of the system (Zedler, 1996).

Nevertheless, it is easy see why managers set narrow compliance goals. Static, structural targets are relatively quick and easy to measure; they simplify the task of accounting for the outcome of a project.
Melding these divergent views is a challenge and a goal for restoration. Multiple values-policy, management, science, values of indigenous peoples, economicsmust be interwoven

\section{to achieve the renewal of ecosystems.}

Functional parameters, on the other hand, are the ultimate in uncertainty because they vary over time and space. Moreover, scientists often have not provided enough data about functional measures to produce ecologically useful objectives for restoration projects. While using functional parameters as goals may make it more difficult for managers to justify the outcome of their policies, developing those parameters is absolutely necessary to determine the long-term viability and ecological sustainability of the system. Restoration is, after all, a process, not a single target.

How then are managers and scientists to set and meet goals assessing ecological functioning in this world of data shortages and natural variability? One approach is for managers to include several ecological process parameters as compliance targets, in addition to their static goals. This would allow scientists to research these ecological parameters as part of the project, and would help advance knowledge about the variability and uncertainty associated with these parameters. Developing goals for ecological processes and implementing a "project-plus-research" approach requires that managers and scientists cooperate throughout the process. Research will provide information to managers on how to improve compliance targets and will add to our knowledge about the relationship between structure and functioning in ecological systems. This approach, though more expensive and time consuming than typical monitoring, is not new and has been used successfully to understand the progress and functioning of restoration projects.

A prime example of this is the research conducted by Joy Zedler and her colleagues at San Diego State University on the Connector Marsh-a mitigation project for wetland losses caused by highway expansion (see REMN 9(1):21-25). A primary goal of the Connector Marsh project was to create cordgrass (Spartina foliosa) habitat to attract the endangered light-footed clapper rail (Rallus longirostris levipes). Although cordgrass was established on the site, Zedler and her colleagues showed that the habitat did not meet important clapper rail requirements for plant height and aboveground biomass. These parameters, in turn, are linked to nutrient fixation rates-an important functional measure of ecosystem dynamics (Zedler, 1996).

In a seven-year study at the Gog-Le$\mathrm{Hi}-\mathrm{Te}$ marsh in Tacoma, Washington, Charles Simenstad of the University of Washington, Ronald Thom of Battelle Northwest Laboratories, and their colleagues found that the marsh is not functioning as expected and may be diverging from the expected ecological community (Simenstad and Thom, 1996). Like the results from Connector Marsh in San Diego, this extensive, multi-year research resulted in data that was applicable to other regional projects and helped managers and scientists link structural parameters to ecological processes.

In addition to generating useful ecological data, this project-plus-research approach produces a dialogue between managers and scientists-perhaps the best way for these two cultures to understand each other's needs and limitations. This dialogue should change the direction of some academic research to help managers meet their goals (Norton, 1998), and encourage managers and scientists to work together to meet challenges of scientific, social and political uncertainties. 
While landscape-level research efforts are essential (Norton, 1998), I believe that linking research to specific projects is a quick way to develop personal relationships between scientists and managers. As has occurred in southern California, project-related interactions and research efforts then highlight the need for largescale, regional research and restoration planning (Zedler, 1996).

\section{Conclusion}

This discussion suggests that restoration projects should be designed to accomplish the following aims:

1) Meet policy needs by including specific compliance targets as well as goals for ecological functioning in projects.

2) Develop a dialogue between scientists and managers by including research in key restoration projects.

3) Design project-related research to answer questions important to managers, to develop structure and function parameters that are useful as compliance goals, to add to our theoretical knowledge, and to reduce uncertainty in ecological data.

4) Improve compliance targets in future projects by incorporating data gained from project-related studies.

5) Publish information or find other methods for its dispersal so that general project findings can help lead to cooperative, large-scale projects.

The Kissimmee River restoration is an example of a project that meets all of these aims. This project has been designed to restore the river's pre-1960s hydrologi$\mathrm{cal}$ and ecological conditions while meeting flood protection needs. Project goals have been defined in terms of process and structure and, where possible, in quantitative terms that allow for natural variation. One hydrological goal, for example, is to achieve average water velocities of "between 0.3 and $0.6 \mathrm{~m}^{3}$ per second when flows are contained within channel banks" (Koebel, 1995). A large-scale "demonstration project" was undertaken

\section{In addition to}

generating useful ecological data, this project-plus-research approach produces a dialogue between managers and scientists-perhaps the best way for these two cultures to understand each other's needs and limitations.

to collect data on biological responses to the hydrological targets. Data from this experiment, historical data and modeling were all used to refine ecological goals and provide data that responded to managers' needs. This feedback process-akin to adaptive management-is one of the reasons Col. Rice believed the process has successfully moved forward in south Florida. Through his interactions with scientists, Col. Rice learned that managers can work with uncertain data if that information can be enhanced and modified with the results obtained from ongoing research.

Although it is often difficult for managers to include and fund research in their projects, this is one of the most direct ways for decision-makers to get answers to questions important to them. Well-designed research and long-term monitoring produce useful information, especially when they are designed with the needs and priorities of the practitioner in mind. The cul- ture of science has not placed high value on applied studies, but the policy-science interaction would benefit from scientists being rewarded for practical research. Scientists must realize that managers make valuable contributions to restoration projects, and practical data needs should be considered in designing experiments and setting research priorities.

Our challenge as restorationists, whether as practitioners or researchers, is to integiate our knowledge and our fields of expertise into an holistic process that meets the needs of society while restoring the natural world we cherish.

Lynne A. Trulio, Associate Professor

Department of Environmental Studies

San Jose State University

San Jose, CA 95192-0116

408/924-5445; FAX 408/924-5477

e-mail: ltrulio@annap.infi.net

\section{REFERENCES}

Carpenter, R.A. 1995. Communicating environmental science uncertainty. The Environmental Professional 17:127-136.

Haeuber, R. and P. Ringold. 1998. Ecology, the social sciences and environmental policy. Ecological Applications 8:330-331.

Jackson, L.L., N. Lopoukhine and D. Hillyard. 1995. Ecological restoration: a definition and comments. Restoration Ecology 3:71-75.

Josselyn, M., J.B. Zedler, J.B. and T. Griswold. 1990. Wetland mitigation along the Pacific coast of the United States. Pages 3.36 in J.A. Kusler and M.E. Kentula, eds., Wetland creation and restoration. Covelo, CA: Island Press.

Koebel, J.W. 1995. An historical perspective on the Kissimmee River restoration project. Restoration Ecology 3:149-159.

Norton, B.A. 1998. Improving ecological communication: the role of ecologists in environmental policy formation. Ecological Applications 8:350-364.

Simenstad, C.A. and R.M. Thom. 1996. Functional equivalency trajectories of the restored $\mathrm{Gog}-\mathrm{Li}-\mathrm{Hi}-\mathrm{Te}$ estuarine wetland. Ecological Applications 6:38-56.

Zedler, J.B. 1996. Coastal mitigation in southern California: the need for a regional restoration strategy. Ecological Applications 6:84-93. 